\title{
Familiarity with radiation exposure dose from diagnostic imaging for acute pulmonary embolism and current patterns of practice
}

\author{
Justin S. Ahn, MD; Marcia L. Edmonds, MD, MSc; Shelley L. McLeod, MSc; Jonathan F. Dreyer, MD
}

\section{ABSTRACT}

Objective: To assess the current level of knowledge and practice patterns of emergency physicians regarding radiation exposure from diagnostic imaging modalities for investigating acute pulmonary embolism (PE).

Methods: An online survey was sent to adult emergency physicians working at two academic tertiary care adult emergency departments (EDs) to determine imaging choices for investigating $P E$ in various patient populations and to assess their current knowledge of radiation doses and risks. A retrospective chart review was performed for all adult patients who underwent computed tomographic pulmonary angiography (CTPA) and/or ventilation-perfusion (V/Q) scanning in the same EDs.

Results: The survey response rate was $72.1 \%$ (31 of 43 physicians). For patients $<30$ years old, $83.9 \%$ of physicians chose $\mathrm{V} / \mathrm{Q}$ scanning as their test of choice, regardless of gender. Although only a third of respondents knew the estimated radiation dose of a V/O scan (37.5\%) and a CTPA $(32 \%)$, the majority were aware that $\mathrm{V} / \mathrm{Q}$ scans involved less ionizing radiation than CTPAs. In the retrospective review, 663 charts were reviewed, including 201 CTPAs and $462 \mathrm{~V} / \mathrm{Q}$ scans. $\mathrm{V} / \mathrm{Q}$ scanning was the preferred modality in female patients (75.9\% v. CTPA $24.1 \%$ [OR 2.1; 95\% Cl 1.5-2.9]) and in patients $<30$ years old (87.9\% v. CTPA $12.1 \%$ [OR $4.8 ; 95 \%$ Cl $2.4-9.4$ ]). Conclusions: Although surveyed physicians possessed limited knowledge of radiation doses of CTPA and V/Q scans, they preferentially used the lower radiation $V / O$ scans in younger patients, particularly females, in both the survey vignettes and in clinical practice. This may reflect efforts to reduce radiation exposures at our institution.

\section{RÉSUMÉ}

Objectif: L'étude visait à évaluer le degré de connaissances des urgentologues et leur pratique en ce qui concerne
I'exposition au rayonnement émis par les différents types d'imagerie diagnostique, dans le contexte de l'embolie pulmonaire (EP) aiguë.

Méthodes: Un questionnaire d'enquête en ligne a été envoyé à des urgentologues travaillant dans deux services d'urgence (SU) universitaires, de soins tertiaires, pour adultes, visant à déterminer le type choisi d'imagerie pour confirmer la présence d'une EP dans différents groupes de patients, et à évaluer leur degré de connaissances sur les doses de rayonnement et leurs risques. Nous avons procédé à un examen rétrospectif des dossiers médicaux de tous les adultes ayant subi une angiographie pulmonaire par tomodensitométrie (APTDM) et/ou une scintigraphie de ventilation et de perfusion (VA/Q) dans ces mêmes SU.

Résultats: Le taux de réponse a atteint $72.1 \%$ (31 médecins sur 43). Chez les patients de moins de 30 ans, $83.9 \%$ des médecins ont choisi la scintigraphie de VA/Q comme examen de première intention, indépendamment du sexe. Un tiers seulement des répondants connaissait la dose estimée de rayonnement de la scintigraphie de VA/Q (37.5\%) et de I'APTDM (32\%), mais la majorité savait que la scintigraphie de VA/Q émettait moins de rayonnement ionisant que I'APTDM. L'examen rétrospectif a permis d'analyser 663 dossiers: 201 faisaient mention d'une APTDM et 462, d'une scintigraphie de $\mathrm{VA} / \mathrm{Q}$. Ce dernier examen s'est révélé la technique préférée d'imagerie chez les femmes $(75.9 \%$ contre $24.1 \%$ pour I'APTDM [risque relatif approché (RRA): 2.1; IC à 95\%: 1.5-2.9]) et chez les patients de moins de 30 ans (87.9\% contre $12.1 \%$ pour I'APTDM [RRA: 4.8 ; IC à $95 \%$ : $2.4-$ 9.4]).

Conclusions: Les médecins qui ont répondu au questionnaire d'enquête avaient peu de connaissances sur les doses de rayonnement émises par I'APTDM et par la scintigraphie de VA/Q; ils ont néanmoins préféré la scintigraphie de VA/Q, dont la dose de rayonnement est faible, à I'APTDM chez les jeunes patients, notamment de sexe féminin, et ce, tant dans les scénarios décrits dans l'enquête qu'en pratique

From the Division of Emergency Medicine, Schulich School of Medicine and Dentistry, Western University, London, ON.

Presented at the Canadian Association of Emergency Physicians Annual Conference, 2011 (St. John's, NL) and 2012 (Niagara Falls, ON).

Correspondence to: Dr. Justin Ahn, Division of Emergency Medicine, Schulich School of Medicine and Dentistry, Western University, London, ON N6A 5W9; jahn49@uwo.ca.

This article has been peer reviewed. 
clinique. Les résultats peuvent témoigner des efforts faits dans notre établissement afin de diminuer l'exposition au rayonnement.
Keywords: computed tomographic pulmonary angiography, diagnostic imaging tests, pulmonary embolism, radiation exposure, ventilation-perfusion scan
There is growing concern in the public and medical community over the biologic effects of ionizing radiation from diagnostic imaging, especially in young adults and women. ${ }^{1-5}$ Young patients are at greatest risk due to the higher proportion of actively dividing cells and longer period of time to accumulate and express radiation-induced malignancies. ${ }^{6}$ Young females are particularly susceptible due to the radiosensitivity of

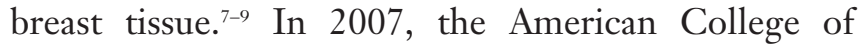
Radiology stated that "the rapid growth of computed tomography (CT) and certain nuclear medicine studies...may result in an increased incidence of radiationrelated cancers in the not too distant future" and that physicians should consider radiation exposure when selecting imaging tests for patients. ${ }^{3}$

Radiation exposure to patients can be reduced by substituting CT with nonionizing imaging investigations such as ultrasonography (US). This has been suggested for the investigation of appendicitis and urolithiasis. ${ }^{10,11}$ When nonionizing imaging modalities are not feasible, the next best option is a test that minimizes radiation exposure.

Chest pain and dyspnea are common emergency department (ED) complaints. In patients in whom acute pulmonary embolism (PE) is suspected, both computed tomographic pulmonary angiography (CTPA) and ventilation-perfusion (V/Q) scanning are useful diagnostic tests. ${ }^{12-14}$ However, the dose of ionizing radiation from a CTPA has been reported to be at least five times greater than that of a V/Q scan, particularly to breast tissue. ${ }^{8,9,15}$ Currently, it is unknown if emergency physicians consider radiation exposure when choosing diagnostic imaging for acute PE.

The primary objective of this study was to assess the current level of knowledge of emergency physicians regarding radiation exposure from diagnostic imaging tests for investigating acute $\mathrm{PE}$. The secondary objective was to determine if physicians chose the test with less ionizing radiation in more radiosensitive populations, both in theoretical patients (assessed by a survey) and in actual practice (assessed by a retrospective chart review).

\section{METHODS}

\section{Survey design and setting}

All emergency physicians working in the two academic tertiary care EDs that are affiliated with Western University (combined annual census 140,000) in London, Ontario, were invited to complete an online survey consisting of 3 baseline demographic questions and 22 questions divided into two sections (Appendix). The first section contained 11 clinical vignettes of patients with varying ages, genders, and comorbidities; the scenarios involved healthy 25 -year-old, healthy 45 -year-old, healthy 60-year-old, and 60-year-old patients with recent head and abdominal CT scans and a 60-year-old patient with breast cancer and chronic obstructive pulmonary disease (COPD). Participants were asked to select which imaging modality they would choose to investigate for $\mathrm{PE}$ for each scenario. To avoid influencing their decision, participants were not informed of the study intent.

After submitting answers to the first section, participants were asked 11 questions regarding their knowledge of radiation doses and risks from common environmental and medical sources. The survey was designed such that participants were required to answer questions in sequence and not permitted to revise previous answers. Survey questions were created by the investigators based on a review of the relevant literature, as well as consultation with emergency medicine residents, physicians, and a clinical epidemiologist. Prior to distribution, the questionnaire was peer reviewed by three emergency physicians unrelated to the study and tested for ease of comprehension. Participation was voluntary and anonymous. Approval for this research study was obtained from the Health Sciences Ethics Board at Western University.

\section{Retrospective review design and setting}

A retrospective electronic medical record review was conducted for all adult ( $\geq 18$ years old) patients who had a V/Q scan or a CTPA ordered by an emergency physician for suspected PE over a 1-year period (April 1, 2009, to March 31, 2010). Patients were excluded if 
they were pregnant, they were undergoing a follow-up study for a PE diagnosed within 90 days, their test was ordered for an indication other than PE, they did not show up for the test, they had a history of chronic PE or deep vein thrombosis (DVT) or a previous diagnosis of PE or DVT within 90 days, or they had imaging ordered by consulting services. All duplicate studies were excluded.

A trained abstractor reviewed the electronic medical records and recorded imaging results, as well as any results from follow-up imaging studies (CTPA, V/Q scanning, or venous US) that had been performed within 90 days of the original investigation using a standardized data collection tool. The following information was also documented: patient age and gender; documented pulmonary, cancer, or thromboembolic comorbidities; calculated glomerular filtration rate (GFR); intravenous contrast allergies; and the number of CT and nuclear medicine scans accumulated over the last 10 years. We considered a positive CTPA to be any test where the final radiology report confirmed a pulmonary vascular filling defect consistent with PE and a negative CTPA to be any test where no vascular filling defect was interpreted. We considered a positive V/Q scan to be any test where the final radiology report read positive or high probability for PE (as per Prospective Investigation of Pulmonary Embolism Diagnosis [PIOPED] criteria) and a negative V/Q scan to be any test reported as normal or negative for PE. ${ }^{16}$ Nondiagnostic VQ scans included indeterminate, very low probability, low probability, or intermediate scans and were considered negative if immediate follow-up imaging (e.g., venous US or CTPA) was negative for DVT or PE or if no follow-up imaging was ordered and the patient did not have a DVT or PE diagnosed within 3 months of the original study by medical record review. We considered a false negative CTPA and V/Q scan to be when the initial radiology interpretation was negative for $\mathrm{PE}$ but follow-up imaging within 3 months of the original study diagnosed either DVT or PE.

\section{Data analysis}

Data were entered directly into a study-specific Microsoft Excel database (Microsoft Corporation, Redmond, WA). Standard descriptive statistics were summarized using means and standard deviations (SDs), and differences in proportions were assessed by the Pearson $\chi^{2}$ statistic. Univariable analysis was used to assess the association between V/Q scans, age, and gender. The results are reported as odds ratios (ORs) with 95\% confidence intervals (CIs). All data analyses were performed using SPSS 19.0 (IBM Corporation, Armonk, NY).

\section{RESULTS}

\section{Physician survey}

Of the 43 emergency physicians invited to participate, $31(72 \%)$ completed the online survey. The majority (71\%) of respondents were male. Years of emergency medicine practice varied from $<5$ years $(33 \%), 5$ to 15 years $(33 \%)$, and $>15$ years $(33 \%)$.

Physicians preferentially chose V/Q scanning for younger patients or if the patients had a history of multiple recent CT scans (Table 1). In contrast, the number of CTPAs chosen increased with advancing

\begin{tabular}{|c|c|c|c|}
\hline \multirow[b]{2}{*}{ Clinical vignette } & \multicolumn{3}{|c|}{ Imaging test chosen } \\
\hline & V/O scanning & CTPA & CTPA and CTV \\
\hline Healthy 25 -year-old female & 26 & 5 & 0 \\
\hline Healthy 25-year-old male & 26 & 5 & 0 \\
\hline Healthy 45-year-old female & 22 & 7 & 0 \\
\hline Healthy 60-year-old female & 16 & 15 & 0 \\
\hline Healthy 60-year-old male, head CT and abdominal CT performed within last year & 26 & 4 & 0 \\
\hline 60-year-old female with breast cancer & 10 & 20 & 1 \\
\hline 60-year-old male with COPD & 2 & 28 & 1 \\
\hline
\end{tabular}


age and comorbidities. The gender of patients did not appear to influence imaging test choices.

When asked if they inform patients about the risks of receiving radiation from diagnostic imaging tests, 58\% of respondents stated that they inform all patients and $35 \%$ only patients deemed to be "high risk" (including pregnant patients and females of childbearing age). One respondent reported informing patients that there are radiation risks, but the degree of risk is unknown, and another reported never informing patients of these risks.

When asked to determine the approximate radiation dose of a CTPA and a V/Q scan expressed in $\mathrm{mSv}$, radiation-absorbed dose (rad), or equivalent number of posteroanterior (PA) chest $\mathrm{x}$-rays, 8 of $25(32 \%)$ and 9 of $24(38 \%)$ respondents chose the correct dose for CTPA and V/Q scanning, respectively (Table 2). These doses were the effective doses determined from a literature search and reported effective doses at our institution. ${ }^{6,15,17}$ Respondents knew that the radiation dose from a V/Q scan is less than that from a CTPA. Only 3 of $26(11 \%)$ respondents were aware that, at the present time, there are no generally accepted limits for cumulative lifetime radiation dose that a patient can safely receive from diagnostic imaging.

\section{Retrospective review}

There were 703 CTPAs and V/Q scans ordered from the two EDs over the 1-year study period. Of these, 40 were excluded (Figure 1), leaving 201 CTPAs and 462 V/Q scans included in this study. The mean (SD) age of all patients was 53.4 (20.3) years, and the majority $(60.6 \%)$ of patients were female. Patients with poor renal function (estimated GFR $<60 \mathrm{~mL} / \mathrm{min}$ ), intravenous contrast allergies, asthma, malignancy, previous DVT, and previous PE were more likely to have a V/Q scan (Table 3).
Overall, the preferred imaging test was V/Q scanning $(69.7 \%)$. When imaging tests were stratified according to age and gender, females and patients $<50$ years old were more likely to get V/Q scanning (Table 4). In particular, $91.9 \%$ of females $<30$ years old received V/Q scanning compared to $76 \%$ of males in the same age category (OR 3.6; 95\% CI 1.1-12). The frequency of CTPAs increased with age and comorbidity in both the survey and the retrospective review.

The overall incidence of venous thromboembolism (VTE) during the study was $13.9 \%$ (92 of 663) (see Figure 1). Of these, 79 were diagnosed on the initial diagnostic test (32 on a CTPA and 47 on a V/Q scan) and 13 were diagnosed on follow-up studies ( 2 on a V/Q scan, 2 on a CTPA, and 9 on a venous sonogram) (Table 5). The most common alternative diagnosis for patients' symptoms seen on CTPAs that were read as negative for $\mathrm{PE}$ was consolidation. Other alternative diagnoses provided by CTPA are listed in Table 6. Alternative diagnoses not seen on a chest $\mathrm{x}$-ray were found in only 1 of $12(8.3 \%)$ CTPAs ordered in patients $<30$ years old (pancreatitis) compared to 28 of 68 (41.2\%) CTPAs ordered in patients $\geq 70$ years old.

Patients $<30$ years old had a higher incidence of diagnostic V/Q scan results (53 of 87 or $60.9 \%$ were normal or high probability), a lower prevalence of comorbidities (9 of 99 or $9.1 \%$ ), and a higher prevalence of normal chest x-rays (84 of 89 or $94.3 \%$ ). In contrast, patients $\geq 70$ years old had a higher incidence of nondiagnostic V/Q scan results (79 of 103 or $76.7 \%$ were very low, low, or intermediate probability or indeterminate scans), a higher prevalence of comorbidities (104 of 171 or $60.8 \%)$, and a lower prevalence of normal chest $\mathrm{x}-$ rays (101 of 168 or $60.11 \%$ ) (Figure 2). The incidence of positive studies for VTE remained relatively stable (8.1$12.6 \%$ ) until age 70 , when the incidence increased dramatically $(22.8 \%)$.

Table 2. Estimated radiation doses (expressed as equivalent number of posterior anterior chest $\mathrm{X}$-rays) of CTPA and V/Q scans chosen by surveyed physicians

\begin{tabular}{|c|c|c|c|c|c|c|}
\hline & \multicolumn{6}{|c|}{ Equivalent number of PA chest $x$-rays } \\
\hline & 20 & 40 & 100 & 200 & 1,000 & Not sure \\
\hline CTPA & 2 & 0 & 8 & 8 & 3 & 4 \\
\hline V/Q & 5 & 9 & 3 & 2 & 0 & 5 \\
\hline
\end{tabular}




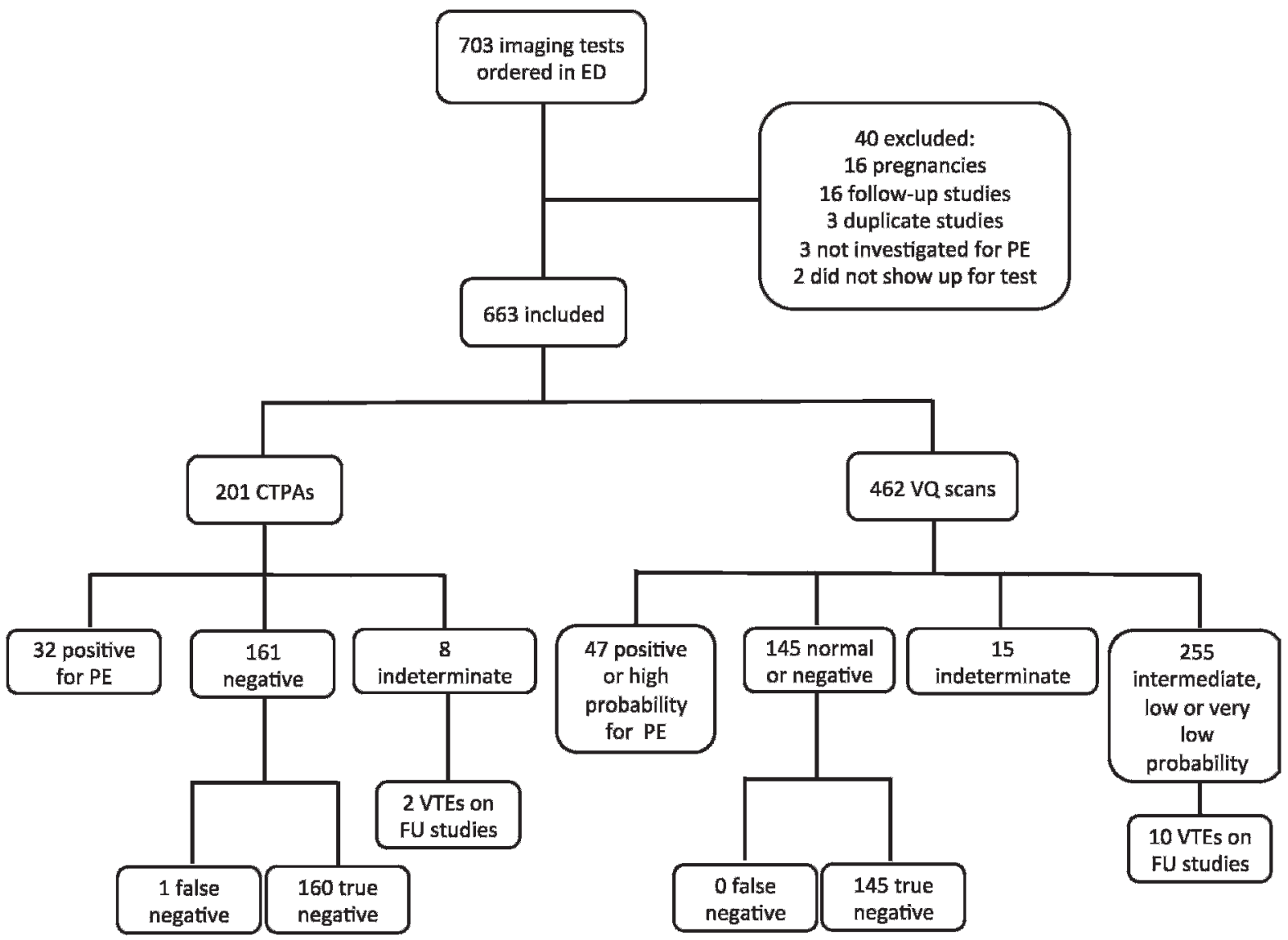

Figure 1. Flow diagram of patients enrolled in the retrospective review. VTE (venous thromboembolism) includes deep vein thrombosis and pulmonary embolism (PE). Follow-up imaging included venous ultrasonography of extremities, computed tomographic pulmonary angiography (CTPA), or ventilation-perfusion scanning (VQ). ED = emergency department; FU = follow-up.

Table 3. Demographics of patients included in the retrospective review

\begin{tabular}{|c|c|c|c|}
\hline & $\mathrm{V} / \mathrm{Q} \operatorname{scan}(n=462)$ & CTPA $(n=201)$ & $\Delta(95 \% \mathrm{Cl})$ \\
\hline Mean age, yr (SD) & $51(20.6)$ & $60(18.0)$ & \\
\hline Female, $n(\%)$ & 305 (75.9) & $97(24.1)$ & $51.8 \%(45.5-57.3)$ \\
\hline Male, $n(\%)$ & $157(60.1)$ & $104(39.8)$ & $20.3 \%(11.8-28.4)$ \\
\hline eGFR $<60 \mathrm{~mL} / \mathrm{min}, n(\%)$ & $66(72.5)$ & $25(27.5)$ & $45.0 \%(31.0-56.5)$ \\
\hline IV contrast allergy, $n(\%)$ & $13(81.2)$ & $3(18.8)$ & $62.5 \%(28.2-79.7)$ \\
\hline \multicolumn{4}{|l|}{ Comorbidity, $n(\%)$} \\
\hline Asthma & $27(61.4)$ & $17(38.6)$ & $24.4 \%(2.8-43.0)$ \\
\hline COPD & $16(41.0)$ & $23(59.0)$ & $-18.0 \%(-37.7-4.1)$ \\
\hline $\mathrm{CHF}$ & $14(41.2)$ & $20(58.8)$ & $-17.6 \%(-38.6-5.8)$ \\
\hline Restrictive lung disease & 4 (33.3) & $8(66.7)$ & $-33.3 \%(-60.9-5.7)$ \\
\hline Malignancy & $66(57.4)$ & $49(42.6)$ & $14.8 \%(1.9-27.0)$ \\
\hline Previous DVT & $37(68.5)$ & $17(31.5)$ & $39.2 \%(20.0-54.6)$ \\
\hline Previous PE & $42(64.6)$ & $23(35.4)$ & $29.2 \%(12.1-44.1)$ \\
\hline Normal chest x-ray, $n(\%)$ & $378 / 443(85.3)$ & $90 / 189$ (47.6) & $37.7 \%(29.8-45.3)$ \\
\hline
\end{tabular}

$\mathrm{CHF}=$ congestive heart failure; COPD = chronic obstructive pulmonary disease; CTPA = computed tomographic pulmonary angiogram; DVT = deep vein thrombosis; eGFR = estimated glomerular filtration rate; IV = intravenous; $\mathrm{PE}=$ pulmonary embolism; $\mathrm{V} / \mathrm{Q}=$ ventilation-perfusion 


\begin{tabular}{|c|c|c|c|}
\hline & $n$ & Odds ratio & $95 \% \mathrm{Cl}$ \\
\hline \multicolumn{4}{|l|}{ Gender only } \\
\hline Female & 402 & 2.1 & $1.5-2.9$ \\
\hline \multicolumn{4}{|l|}{ Age only } \\
\hline $18-30 \mathrm{yr}$ & 99 & 4.8 & $2.4-9.4$ \\
\hline $30-49 \mathrm{yr}$ & 211 & 2.1 & $1.3-3.2$ \\
\hline $50-69 \mathrm{yr}$ & 182 & 1.1 & $0.7-1.7$ \\
\hline$\geq 70 \mathrm{yr}$ & 171 & Ref. & Ref. \\
\hline \multicolumn{4}{|c|}{ Age and gender } \\
\hline Age $18-30 \mathrm{yr}$ & 99 & & \\
\hline Male & 25 & 1.5 & $0.5-4.0$ \\
\hline Female & 74 & 5.3 & $2.1-13.3$ \\
\hline Age $30-49$ yr & 211 & & \\
\hline Male & 84 & 0.9 & $0.5-1.7$ \\
\hline Female & 127 & 2.1 & $1.2-3.9$ \\
\hline Age 50-69 yr & 182 & & \\
\hline Male & 91 & 0.7 & $0.4-1.3$ \\
\hline Female & 91 & 0.8 & $0.5-1.4$ \\
\hline Age $\geq 70 \mathrm{yr}$ & 171 & & \\
\hline Male & 61 & 0.4 & $0.2-0.7$ \\
\hline Female & 110 & Ref. & Ref. \\
\hline
\end{tabular}

A retrospective review of the electronic medical records of patients included in this study revealed that, cumulatively, they had undergone 1,930 computed tomographic (CT) and nuclear medicine scans in the 10 -year period prior to this study being conducted.
This equates to a median (interquartile range) of 5 (3-7) ionizing radiation scans per person. Of all 663 patients reviewed, 223 (33.6\%) patients had no documented previous scans, of which 65 patients were in the $<30$ years old age group (65 of 99). Of the 440 patients who had at least one previous ionizing scan, $270(61.3 \%)$ patients had 1 to 4 previous scans, 127 (28.9\%) patients had 5 to 9 scans, and 43 (9.8\%) patients had 10 or more scans. In the latter group, 9 patients were $<50$ years old. The maximum number of scans documented per patient was $22(n=2)$. The most common comorbidities among patients who had undergone multiple scans were a history of cancer $(n=$ $25)$, previous $\mathrm{PE}(n=13)$, and pulmonary diseases such as COPD and interstitial lung disease $(n=12)$.

\section{DISCUSSION}

This study examined the current level of knowledge of the relative doses of radiation exposure from two common imaging modalities used by emergency physicians to diagnose acute PE. It also determined whether physicians chose the test with less ionizing radiation in more radiosensitive populations, both in theoretical patients and in actual practice.

Precise knowledge of estimated radiation doses was poor among survey respondents, but most physicians knew that V/Q scans exposed patients to less radiation than CTPAs. Physicians at our institution appeared to be cognizant of radiation exposure risks as they

\begin{tabular}{|c|c|c|c|c|c|}
\hline & \multirow[b]{2}{*}{ Results of initial diagnostic test } & \multicolumn{4}{|c|}{ Results of follow-up tests } \\
\hline & & No FU & FU US positive* & FU CTPA positive* & $\begin{array}{l}\text { FU V/Q high } \\
\text { probability* }\end{array}$ \\
\hline \multirow[t]{5}{*}{$\mathrm{V} / \mathrm{Q}(n=462)$} & High/positive ( $n=47)$ & 27 & $6 / 12$ & $3 / 8$ & $4 / 4$ \\
\hline & Intermediate $(n=40)$ & 0 & $2 / 33^{\dagger}$ & $2 / 18^{\dagger}$ & $0 / 1$ \\
\hline & Low/very low $(n=215)$ & 90 & $7 / 124$ & $0 / 10$ & $0 / 3$ \\
\hline & Indeterminate $(n=15)$ & 5 & $0 / 3$ & $0 / 8$ & $0 / 1$ \\
\hline & Normal/negative $(n=145)$ & 124 & $0 / 19$ & $0 / 3$ & $0 / 1$ \\
\hline \multirow[t]{6}{*}{ CTPA $(n=201)$} & Positive ( $n=32$ ) & 24 & $1 / 7$ & $0 / 1$ & $1 / 2$ \\
\hline & Subsegmental $(n=5)$ & & & & \\
\hline & Segmental $(n=23)$ & & & & \\
\hline & Massive $(n=4)$ & & & & \\
\hline & Indeterminate $(n=8)$ & 3 & $0 / 4$ & $0 / 1$ & $2 / 4$ \\
\hline & Negative $(n=161)$ & 131 & $0 / 23$ & $1 / 7$ & $0 / 6$ \\
\hline
\end{tabular}




\begin{tabular}{ll|}
\hline $\begin{array}{l}\text { Table 6. Alternative diagnoses seen on CTPA negative for } \\
\text { pulmonary embolism }\end{array}$ \\
\hline Diagnosis & $n$ \\
\hline No alternative diagnoses & 83 \\
Alternative diagnoses not seen on initial CXR & 49 \\
Consolidation & 9 \\
Pulmonary edema & 7 \\
Aspiration & 6 \\
Pericardial effusion & 5 \\
New nodule/tumour & 4 \\
Rib fractures & 3 \\
Inflammatory lung disease & 3 \\
Septic emboli & 2 \\
Empyema & 2 \\
Bronchiectasis & 2 \\
Pleural effusion & 1 \\
Pericarditis without effusion & 1 \\
Aortic pseudocoarctation & 1 \\
Splenic artery aneurysm & 1 \\
Foreign body & 1 \\
Pancreatitis & 1 \\
\hline CTPA = computed tomographic pulmonary angiogram; CXR = chest x-ray. \\
One patient with a positive CTPA for pulmonary embolism also had \\
pneumomediastinum, pericardial effusion, known lung mass, and consolidation seen on \\
a CXR. \\
\hline
\end{tabular}

preferentially chose the lower ionizing radiation dose V/Q scan in younger patients $(<50$ years old $)$ in the survey. These results were validated by the retrospective chart review, where physicians selected V/Q scans for the majority of patients $<50$ years old. In contrast to the survey results, where gender did not appear to be a decisive factor, in actual practice, physicians preferentially chose V/Q scans for females compared to males in similar age categories. This may

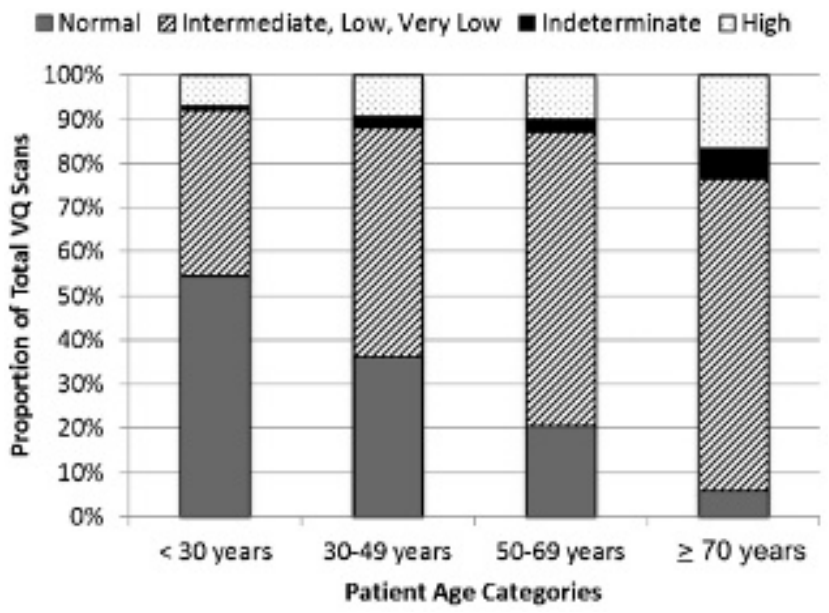

Figure 2. Ventilation-perfusion (VQ) scan results stratified by age. reflect the influence of patient interaction that could not be reproduced in the clinical vignettes.

The literature suggests that there is good evidence of an increase in cancer risk from intermediate doses of radiation. ${ }^{6}$ The Biological Effects of Ionizing Radiation VII report supports the current theory that this cancer risk can be extrapolated to the very low dose patients are exposed to from diagnostic imaging tests. ${ }^{2}$ To date, there have been no prospective studies examining the effects of ionizing radiation from diagnostic imaging on the development of malignancies. Multiple cohort studies have estimated the detrimental effects of ionizing radiation from diagnostic imaging. However, the majority of the risk estimates for the development of solid cancers and leukemia have been derived from atomic bomb survivors in Hiroshima and Nagasaki. ${ }^{18,19}$ A recent retrospective cohort study examined the effect of radiation exposure from CT scans in 178,604 children over a 20-year follow-up period and was the first study to directly correlate the cancer risk from medical imaging tests. ${ }^{20}$ The study found that compared to people who had received doses $<5 \mathrm{mGy}(<5 \mathrm{mSv})$, the relative risk of leukemia for patients who received at least $30 \mathrm{mGy}(30 \mathrm{mSv})$ was 3.18 (95\% CI 1.46-6.94), and the relative risk for brain tumours for patients who received at least $50 \mathrm{mGy}$ (50 mSv) was 3.32 (95\% CI 1.84-6.42). This equated to a risk of one excess case of leukemia and one excess brain tumour per 10,000 head CT scans, 10 years after the first scan in children under 10 years old. ${ }^{20}$ These risks have not yet been studied in young adults, but the increased risk of inducing malignancy from irradiating younger tissue appears certain..$^{20,21}$

Despite the recent increased interest in radiation exposure in the literature, there appears to be a need to improve physicians' knowledge about radiation exposure from diagnostic imaging. A study by Lee and colleagues reported that $73 \%$ of emergency physicians significantly underestimated the radiation dose from a CT scan and that $91 \%$ of emergency physicians did not believe that CT scans increased the lifetime risk of cancer. ${ }^{22}$ Another recent survey revealed that $77 \%$ of nonradiologists (20.3\% of respondents were emergency physicians) underestimated the doses of common diagnostic imaging tests, and approximately one-third could not distinguish between ionizing (e.g., radioisotope scans) and nonionizing (e.g., magnetic resonance imaging) scans. ${ }^{23}$

Improving education will also provide physicians with the background knowledge needed to accurately 
inform patients of the risks prior to performing imaging studies. Only 3 to $13 \%$ of patients believe that exposure to ionizing radiation from diagnostic imaging tests increases their risk of cancer..$^{22,24}$ Nearly half (47\%) of these patients stated they were informed of these risks, but only $22 \%$ of emergency physicians indicated that they provided their patients with this information. ${ }^{22}$ This is in contrast to our study, in which $93 \%$ of physicians stated that they inform all high-risk patients of these risks and 58\% inform all of their patients of these risks. However, the disclosure of these risks to patients in clinical practice was not examined, and the type and amount of information physicians actually provide to patients in a clinical setting are unknown.

The most effective way to reduce radiation exposure to patients is the judicious selection of imaging tests. The recent "Choosing Wisely" campaign initiated by the American Board of Internal Medicine and supported by the American College of Radiology and American College of Physicians favours reducing the number of imaging tests ordered to investigate for VTE..$^{25-27}$ In one particular study, up to one-third of imaging procedures performed on low-risk patients $(1,205$ of 4,113) were deemed unnecessary and could potentially have been avoided with proper use of Ddimer testing. ${ }^{28}$

In a recent study, investigators delivered educational seminars to physicians in the departments of emergency medicine, radiology, and nuclear medicine regarding radiation doses and the utility of V/Q and CTPA when investigating patients for PE. ${ }^{29}$ After the seminars, the number of V/Q scans increased, whereas the number of CTPAs decreased, leading to a decreased radiation burden for their patients. This occurred without an increase in missed diagnoses of thromboembolic disease, as determined retrospectively by following patients for 90 days after their initial imaging test. Thus, increased use of V/Q scans in younger patients, particularly women, follows the "as low as reasonably achievable" (ALARA) principle for reducing radiation exposure to patients. ${ }^{30,31}$

Despite efforts to reduce radiation exposure, the use of V/Q scans has been declining since the introduction of CTPA. Between 2006 and 2009, the vast majority of scans ordered in the United States to investigate acute PE were CTPAs, even in teenage $(<20$ year old) males (92\%) and females (90\%). ${ }^{32}$ The advantages of CTPA include direct visualization of thrombus, simple positive or negative results, the provision of alternative explanations for symptoms, and improved accuracy compared to V/Q scans. ${ }^{13}$

The sensitivity and specificity of V/Q and CTPA scans vary depending on the study. A recent prospective trial that performed $\mathrm{V} / \mathrm{Q}$, chest $\mathrm{x}$-ray, and CTPA in all patients presenting with suspected $\mathrm{PE}$ found that the sensitivity of VQ scans was highest using the Prospective Investigative Study of Acute Pulmonary Embolism Diagnosis (PISAPED) criteria $(86.0 \%)$ compared to 64-slice CTPA $(81.7 \%)$ and that the proportion of nondiagnostic scans was lower $(0 \%)$ compared to the PIOPED II criteria (12.3\%). ${ }^{33,34}$ The specificity of CTPA is consistently higher than that of V/Q scanning, and the proportion of CTPAs positive for $\mathrm{PE}$ is higher than that for V/Q scans. ${ }^{13,33}$ However, the clinical significance of subsegmental PE seen on CTPA is controversial because the mortality from $\mathrm{PE}$ remains unchanged despite an increase in the number of PEs diagnosed. ${ }^{35}$ A recent systematic review and metaanalysis found that despite increased diagnoses of subsegmental PEs using multiple-detector CTPA compared to single-detector CTPA $(9.4 \%$ v. $4.7 \%$, respectively), improved detection did not lower the 3-month risk of thromboembolism in untreated patients with initial negative CTPAs $(1.1 \%$ in multiple-detectors CTPAs and $0.9 \%$ in single-detector CTPAs)..$^{36}$ Small studies involving patients with untreated subsegmental PEs were found to have no fatal recurrences in 1 to 3 months and no nonfatal recurrences of PE in 3 months. ${ }^{37}$

Studies examining investigation of $\mathrm{PE}$ often include adult patients of all ages. In our study, we found that the proportion of diagnostic V/Q scans was highest in patients $<30$ years old. This correlated with a higher incidence of normal chest x-rays, fewer pulmonary or cancer comorbidities, and a lower frequency of alternative diagnoses provided by CTPA. These factors, combined with the reduced radiation exposure, make V/Q scanning a more appropriate test for younger radiosensitive populations. However, this needs to be examined prospectively in future studies. Low or nonionizing alternatives to V/Q scanning include singlephoton emission computed tomography (SPECT), which is a three-dimensional nuclear medicine scan that shows comparable sensitivity and specificity to those of CTPA; pulmonary magnetic resonance angiography and venography; and the reduction of CTPA radiation dosages through technical (e.g., adjust voltage or current, limit $z$-axis coverage) or traditional (e.g., shielding) strategies, but further investigation is required..$^{13,38-41}$ 


\section{LIMITATIONS}

This study has several limitations. First, the survey was distributed to physicians working in two Canadian tertiary care adult EDs, and as such, the results may not be generalizable to other settings. The applicability of these findings is limited to institutions that have access to V/Q scans. At our institution, it is standard practice to order V/Q scans for investigation of acute PE in ED patients with a normal chest $\mathrm{x}$-ray. This may not be the usual practice in other EDs. V/Q scans are available daily from $0800-1600$, with a technologist on call until midnight. In contrast, CT is available 24 hours a day.

In addition to radiation risk, other factors are involved when choosing an imaging study that were not investigated in this study, such as patient comorbidities (e.g., renal failure), contrast allergies, and institutional preferences. These issues could be addressed in a prospective study in which physicians would be asked to justify their reasons for choosing a particular diagnostic imaging test.

Lastly, this was a retrospective study, and patients were followed for 90 days after their initial imaging study by electronic medical record review. Although it is theoretically possible that we may have underestimated the incidence of missed PE in our sample as a consequence, this is unlikely because all centres that have CTPA and/or V/Q capability within $50 \mathrm{~km}$ of our hospitals share the same electronic medical record. Most patients were likely to return to one of these EDs for follow-up. The incidence of $\mathrm{PE}$ diagnosed on the initial CTPA (15.9\%) and V/Q scan $(10 \%)$ in our study compares favourably to that of the prospective study by Anderson and colleagues, conducted at four Canadian and one US tertiary care centre, in which the incidence of PE diagnosed with the initial CTPA was $17.7 \%$ and $11.7 \%$ with the initial V/Q scan. ${ }^{12}$ The overall incidence of $\mathrm{PE}$ in that study was $17.2 \%$, which was slightly higher than in our study (13.9\%). However, no fatal cases of missed PE were identified in our retrospective review, and as discussed, the clinical significance of minor PEs, especially those found by CTPA, remains uncertain. ${ }^{13,33}$

\section{CONCLUSIONS}

The most effective method of reducing radiation exposure from diagnostic imaging is the judicious selection of patients who will undergo these investigations. This study demonstrated that although physicians at our institution had limited knowledge of actual radiation doses associated with CTPA and V/Q scans, they were aware that V/Q scans expose patients to less ionizing radiation. In practice, they preferentially chose the lower ionizing V/Q scan in radiosensitive populations. Further evidence-based education of physicians and medical trainees is needed to ensure informed decision making and accurate disclosure of radiation exposure risks to our patients.

Competing interests: None declared.

\section{REFERENCES}

1. Ron E. Cancer risks from medical radiation. Health Phys 2003;85:47-59, doi:10.1097/00004032-200307000-00011.

2. Committee to Assess Health Risks from Exposure to Low Levels of Ionizing Radiation. Health risks from exposure to low levels of ionizing radiation. BEIR VII Phase 2. Washington (DC): The National Academies Press; 2006.

3. Amis ES Jr, Butler PF, Applegate KE, et al. American College of Radiology white paper on radiation dose in medicine. 7 Am Coll Radiol 2007;4:272-84, doi:10.1016/j. jacr.2007.03.002.

4. Brenner DJ, Hall EJ. Computed tomography - an increasing source of radiation exposure. N Engl f Med 2007;357:227784, doi:10.1056/NEJMra072149.

5. Griffey RT. Cumulative radiation exposure and cancer risk estimates in emergency department patients undergoing repeat or multiple CT. A7R Am 7 Roentgenol 2009;192:88792, doi:10.2214/AJR.08.1351.

6. Brenner DJ, Doll R, Goodhead DT, et al. Cancer risks attributable to low doses of ionizing radiation: assessing what we really know. Proc Natl Acad Sci U S A 2003;100:13761-6, doi:10.1073/pnas.2235592100.

7. Tokunaga M, Land CE, Tokuoka S, et al. Incidence of female breast cancer among atomic bomb survivors, 19501985. Radiat Res 1994;138:209-23, doi:10.2307/3578591.

8. Parker MS, Hui FK, Camacho MA, et al. Female breast radiation exposure during CT pulmonary angiography. Am $\mathcal{f}$ Radiol 2005;185:1228-33.

9. Hurwitz LM, Reiman RE, Yoshizumi TT, et al. Radiation dose from contemporary cardiothoracic multidetector CT protocols with anthropomorphic female phantom: implications for cancer induction. Radiology 2007;245:742-50, doi:10.1148/radiol.2453062046.

10. Kessler N, Cyteval C, Gallix B, et al. Appendicitis: evaluation of sensitivity, specificity, and predictive values of US, Doppler US, and laboratory findings. Radiology 2004; 230:472-8, doi:10.1148/radiol.2302021520.

11. Edmonds ML, Yan JW, Sedran RJ, et al. The utility of renal ultrasonography in the diagnosis of renal colic in emergency department patients. CFEM 2010;12:201-6.

12. Anderson DR, Kahn SR, Rodger MA, et al. Computed tomographic pulmonary angiography vs ventilation-perfusion lung scanning in patients with suspected pulmonary embolism: 
a randomized controlled trial. $7 A M A$ 2007;23:2743-53, doi: 10.1001/jama.298.23.2743.

13. Anderson DR, Barnes DV. Computerized tomographic pulmonary angiography versus ventilation perfusion lung scanning for the diagnosis of pulmonary embolism. Curr Opin Pulm Med 2009;15:425-9, doi:10.1097/MCP.0b013e 32832d6b98.

14. Sostman HD, Stein PD, Gottschalk A, et al. Acute pulmonary embolism: sensitivity and specificity of ventilation-perfusion scintigraphy in PIOPED II study. Radiology 2008;246:941-6, doi:10.1148/radiol.2463070270.

15. Mettler FA Jr, Huda W, Yoshizumi TT, et al. Effective doses in radiology and diagnostic nuclear medicine: a catalog. Radiology 2008;248:254-8, doi:10.1148/radiol.2481071451.

16. The PIOPED Investigators. Value of the ventilation/ perfusion scan in acute pulmonary embolism: results of the prospective investigation of pulmonary embolism diagnosis (PIOPED). FAMA 1990;263:2753-9, doi:10.1001/jama.1990. 03440200057023.

17. Leung AN, Bull TM, Jaeschke R, et al. American Thoracic Society documents: an official American Thoracic Society/ Society of Thoracic Radiology clinical practice guidelineevaluation of suspected pulmonary embolism in pregnancy. Radiology 2012;262:635-46, doi:10.1148/radiol.11114045.

18. Pierce DA, Preston DL. Radiation-related cancer risks at low doses among atomic bomb survivors. Radiat Res 2000;154:17886, doi:10.1667/0033-7587(2000)154[0178:RRCRAL]2.0.CO;2.

19. Preston DL, Shimizu Y, Pierce DA, et al. Studies of mortality of atomic bomb survivors. Report 13: solid cancer and noncancer disease mortality: 1950-1997 Radiat Res 2003; 160:381-407, doi:10.1667/RR3049.

20. Pearce MS, Salotti JA, Little MP, et al. Radiation exposure from CT scans in childhood and subsequent risk of leukemia and brain tumours: a retrospective cohort study. Lancet 2012; 380:499-505, doi:10.1016/S0140-6736(12)60815-0.

21. Berrington de Gonzalez A, Mahesh M, Kim KP, et al. Projected cancer risks from computed tomographic scans performed in the United States in 2007. Arch Intern Med 2009;169:2071-7, doi:10.1001/archinternmed.2009.440.

22. Lee CI, Haims AH, Monico EP, et al. Diagnostic CT scans: assessment of patient, physician, and radiologist awareness of radiation dose and possible risks. Radiology 2004;231:393-8, doi:10.1148/radiol.2312030767.

23. Lee RKL, Chu WCW, Graham CA, et al. Knowledge of radiation exposure in common radiological investigations: a compromise between radiologists and non-radiologists. Emerg Med 7 2012;29:306-8, doi:10.1136/emermed-2011-200481.

24. Baumann BM, Chen EH, Mills AM, et al. Patient perceptions of computed tomographic imaging and their understanding of radiation risk and exposure. Ann Emerg Med 2011;58:1-7.e2, doi:10.1016/j.annemergmed.2010.10.018.

25. Cassel CK, Guest JA. Choosing wisely. Helping physicians and patients make smart decisions about their care. $7 A M A$ 2012;307:1801-2, doi:10.1001/jama.2012.476.

26. American College of Physicians. Choosing wisely. Available at: http://www.choosingwisely.org/doctor-patient-lists/americancollege-of-physicians (accessed February 23, 2013).

27. Neeman N, Quinn K, Soni K, et al. Reducing radiology use on an inpatient medical service: choosing wisely. Arch Intern Med 2012;172:1606-7, doi:10.1001/archinternmed.2012.4293.
28. Venkatesh AK, Kline JA, Courtney M, et al. Evaluation of pulmonary embolism in the emergency department and consistency with a national quality measure. Quantifying the opportunity for improvement. Arch Intern Med 2012;172: 1028-32, doi:10.1001/archinternmed.2012.1804.

29. Stein EG, Haramati LB, Chamarthy M, et al. Success of a safe and simple algorithm to reduce use of CT pulmonary angiography in the emergency department. A7R Am 7 Roentgenol 2010;194:392-7, doi:10.2214/AJR.09.2499.

30. Prasad KN, Cole WC, Haase GM. Radiation protection in humans: extending the concept of as low as reasonable achievable (ALARA) from dose to biological damage. $\operatorname{Br} 7$ Radiol 2004;77:97-9, doi:10.1259/bjr/88081058.

31. Schembri GP, Miller AE, Smart R. Radiation dosimetry and safety issues in the investigation of pulmonary embolism. Semin Nucl Med 2010;40:442-54, doi:10.1053/j.semnuclmed. 2010.07.007.

32. Stein PD, Matta F. Noninvasive imaging in pulmonary embolism according to age and gender. Clin Appl Thromb Hemost 2012. DOI:10.1177/107602961262763.

33. He J, Wang F, Dai H, et al. Chinese multi-center study of lung scintigraphy and CT pulmonary angiography for the diagnosis of pulmonary embolism. Int 7 Cardiovasc Imaging 2012;28:1799-805, doi:10.1007/s10554-012-0013-9.

34. Miniati M, Pistolesi M, Marini C, et al. Value of perfusion lung scan in the diagnosis of pulmonary embolism: results of the prospective investigative study or acute pulmonary embolism diagnosis (PISA-PED). Am 7 Respir Crit Care Med 1996;154:1387-93, doi:10.1164/ajrccm.154.5.8912753.

35. Carrier M, Righini M, Le Gal G. Symptomatic subsegmental pulmonary embolism: what is the next step? 7 Thromb Haemost 2012;10:1486-90, doi:10.1111/j.1538-7836.2012.04804.x.

36. Carrier M, Righini M, Wells PS, et al. Subsegmental pulmonary embolism diagnosed by computed tomography: incidence and clinical implications. A systematic review and meta-analysis of the management outcome studies. 7 Thromb Haemost 2010;8:1716-22, doi:10.1111/j.1538-7836.2010.03938.x.

37. Stein PD, Goodman LR, Hull RD, et al. Diagnosis and management of isolated subsegmental pulmonary embolism: review and assessment of options. Clin Appl Thromb Hemost 2012;18:20-6, doi:10.1177/1076029611422363.

38. Miles S, Rogers KM, Thomas P, et al. A comparison of singlephoton emission CT lung scintigraphy and CT pulmonary angiography for the diagnosis of pulmonary embolism. Chest 2009;136:1546-53, doi:10.1378/chest.09-0361.

39. Hurwitz LM, Toshizumi TT, Goodman PH, et al. Radiation dose savings for adult pulmonary embolus 64MDCT using Bismuth breast shields, lower peak kilo voltage and automatic tube current modulation. A7R Am 7 Roentgenol 2009;192:244-53, doi:10.2214/AJR.08.1066.

40. Heyer CM, Mohr PS, Lemburg SP, et al. Image quality and radiation exposure at pulmonary CT angiography with 100 - or $120-\mathrm{kVp}$ protocol: prospective randomized study. Radiology 2007;245:577-83, doi:10.1148/radiol.2452 061919

41. Woo JKH, Chiu RYW, Thakur Y, et al. Risk-benefit analysis of pulmonary CT angiography in patients with suspected pulmonary embolus. AfR Am 7 Roentgenol 2012; 198:1332-9, doi:10.2214/AJR.10.6329. 
APPENDIX: SURVEY QUESTIONS DELIVERED TO ADULT EMERGENCY PHYSICIANS

Demographics

1. Gender

Male

Female

2. Years in practice

$$
\begin{aligned}
& <5 \text { years } \\
& 5-10 \text { years } \\
& 10-15 \text { years } \\
& 15-20 \text { years } \\
& 20 \text { years }
\end{aligned}
$$

3. Which guidelines do you follow for investigating venous thromboembolism?

Published guidelines (e.g., British Thoracic Society) Local guidelines

All of the above

Neither

Clinical Vignettes

You are working the weekday daytime shift at a tertiary care emergency department where all of the listed investigations are available. What would be YOUR initial investigation of choice for the following patients presenting with pleuritic chest pain and shortness of breath. Assume a high pretest probability of $\mathrm{PE}($ Wells score $\geq 4$ ) or a positive $\mathrm{D}$-dimer.

US venous Doppler ultrasonography

CT pulmonary angiography

CT pulmonary angiography with CT leg venography Ventilation-perfusion scanning

Other

4. 25-year-old female. Otherwise healthy. Not pregnant. Chest $\mathrm{x}$-ray is nondiagnostic.

5. 25-year-old female. Otherwise healthy. Pregnant $<20$ weeks gestational age. Chest $\mathrm{x}$-ray is nondiagnostic.

6. 25-year-old male. Otherwise healthy. Chest x-ray is nondiagnostic.

7. 45-year-old female. Otherwise healthy. Not pregnant. Chest $\mathrm{x}$-ray is nondiagnostic.

8. 45-year-old female. Otherwise healthy. Previous V/Q scan 1 year ago, which was normal. Chest $\mathrm{x}^{-}$ ray is nondiagnostic.

9. 45-year-old female. Otherwise healthy. Previous CTPA 1 year ago, which was normal. Chest x-ray is nondiagnostic.
10. 45-year-old male. Otherwise healthy. Previous head CT 1 year ago for fall, which was normal, and previous abdominal CT 2 months ago for diverticulitis. Chest $\mathrm{x}$-ray is nondiagnostic.

11. 60-year-old male. Otherwise healthy. Chest x-ray is nondiagnostic.

12. 60-year-old female. History of left breast cancer treated with left total mastectomy and radiation therapy 5 years ago. Chest $\mathrm{x}$-ray is nondiagnostic.

13. 60-year-old male. History of intracerebral hemorrhage 5 years ago. Chest $\mathrm{x}$-ray is nondiagnostic.

14. 60-year-old male. History of COPD and smoker $\times 40$ pack-years. Chest $\mathrm{x}$-ray shows mild hyperinflation but is otherwise nondiagnostic.

Radiation Exposure Questions

15. Do you explain the radiation risks of diagnostic imaging tests to patients?

Yes

No

Only to pregnant females and females of childbearing age

- All patients who you deem to be at high risk, including pregnant females and females of childbearing age

- Other

16. Do you possess knowledge regarding cancer risks associated with diagnostic imaging radiation?

Yes

No

17. What is the average background radiation dose per person, per year?

$1 \mathrm{PA}$ CXR $(0.05 \mathrm{mSv}$ or $0.005 \mathrm{rad})$

2 PA CXRs $(0.1 \mathrm{mSv}$ or $0.01 \mathrm{rad})$

40 PA CXRs (2 mSv or $0.2 \mathrm{rad})$

100 PA CXRs $(5 \mathrm{mSv}$ or $0.5 \mathrm{rad})$

200 PA CXRs $(10 \mathrm{mSv}$ or $1 \mathrm{rad})$

Not sure

18. The North American population is exposed to radiation from various sources. Of these, medical radiation contributes to
$<0.5 \%$
$1 \%$
$5 \%$
$10 \%$
$15 \%$ 
- Not sure

19. What is the approximate radiation exposure during a round-trip commercial airline flight between New York and London, England (12to 14 -hour trip over $11,000 \mathrm{~km}$ total)?

1 PA CXR (0.05 mSv or $0.005 \mathrm{rad})$

2 PA CXRs $(0.1 \mathrm{mSv}$ or $0.01 \mathrm{rad})$

40 PA CXRs $(2 \mathrm{mSv}$ or $0.2 \mathrm{rad})$

100 PA CXRs $(5 \mathrm{mSv}$ or $0.5 \mathrm{rad})$

Not sure

20. What is the acceptable yearly maximum radiation dosage for radiation workers?

100 PA CXRs (5 mSv or $0.5 \mathrm{rad})$

200 PA CXRs $(10 \mathrm{mSv}$ or $1 \mathrm{rad})$

400 PA CXRs $(20 \mathrm{mSv}$ or $2 \mathrm{rad})$

1,000 PA CXRs (50 $\mathrm{mSv}$ or $5 \mathrm{rad})$

No limit

Not sure

21. What is the acceptable yearly maximum radiation dosage for diagnostic imaging in patients?

100 PA CXRs $(5 \mathrm{mSv}$ or $0.5 \mathrm{rad})$

200 PA CXRs $(10 \mathrm{mSv}$ or $1 \mathrm{rad})$

400 PA CXRs ( $20 \mathrm{mSv}$ or $2 \mathrm{rad})$

1,000 PA CXRs $(50 \mathrm{mSv}$ or $5 \mathrm{rad})$

No limit

Not sure

22. What is the minimum in utero radiation dosage that has been associated with significant and quantifiable increase in the risk of childhood cancers?

2 PA CXRs $(0.1 \mathrm{mSv}$ or $0.01 \mathrm{rad})$

20 PA CXRs $(1 \mathrm{mSv}$ or $0.1 \mathrm{rad})$

100 PA CXRs $(5 \mathrm{mSv}$ or $0.5 \mathrm{rad})$
200 PA CXRs $(10 \mathrm{mSv}$ or $1 \mathrm{rad})$

- 300 PA CXRs $(15 \mathrm{mSv}$ or $1.5 \mathrm{rad})$

- Not sure

23. What is the approximate radiation dosage of a CT pulmonary angiography?

- 20 PA CXRs $(1 \mathrm{mSv}$ or $0.1 \mathrm{rad})$

40 PA CXRs $(2 \mathrm{mSv}$ or $0.2 \mathrm{rad})$

100 PA CXRs $(5 \mathrm{mSv}$ or $0.5 \mathrm{rad})$

200 PA CXRs $(10 \mathrm{mSv}$ or $1 \mathrm{rad})$

- 1,000 PA CXRs (50 mSv or $5 \mathrm{rad})$

24. What is the approximate radiation dosage of a ventilation-perfusion scan?
20 PA CXRs ( $1 \mathrm{mSv}$ or $0.1 \mathrm{rad})$
40 PA CXRs $(2 \mathrm{mSv}$ or $0.2 \mathrm{rad})$
100 PA CXRs $(5 \mathrm{mSv}$ or $0.5 \mathrm{rad})$
200 PA CXRs $(10 \mathrm{mSv}$ or $1 \mathrm{rad})$
1,000 PA CXRs (50 mSv or $5 \mathrm{rad})$

25. The estimated lifetime risk of developing cancer after receiving $10 \mathrm{mSv}$ of radiation (200 PA CXRs) is equivalent to

- 1 in 4.7 million (risk of contracting human immunodeficiency virus [HIV] from a single blood transfusion)

- 1 in 3.1 million (risk of contracting hepatitis C virus from a single blood transfusion)

- 1 in 82,000 (risk of contracting hepatitis B virus from a single blood transfusion)

- 1 in 40,000 (risk of anaphylactic reaction from a single blood transfusion)

- 1 in 5,000 (risk of transfusion-related acute lung injury)

1 in 1,000

Not sure 